\title{
Editorials
}

\section{In celebration of GP education}

\section{INTRODUCTION}

Primary care is at the heart of improving patient health outcomes. ${ }^{1}$ Recognising this, the General Practice Five Year Forward View explicitly sets an annual target of recruiting 3250 doctors in postgraduate GP training across England. ${ }^{2}$ The Royal College of General Practitioners, working with educational commissioners, has worked to increase the number of doctors entering GP training with significant success, although it is unclear to what extent training GPs will convert into service GPs. ${ }^{3}$

Part of the reason for successful recruitment to GP training has been the reputation of postgraduate education in general practice for its learner-centred approach. GP education has been at the cutting edge of improving learner experience through innovations in educational delivery, curriculum, and assessment development, together with strategically influencing medical education policy. The General Medical Council's national trainee survey tells us that GP trainees rate their postgraduate training experience highly, relative to other specialty groups. This is all the more remarkable given the high workloads reported by GP trainers, and this reflects their dedication to training the future workforce.

Robert Francis QC, in his seminal report on the Mid Staffordshire Inquiry, ${ }_{1}^{5}$ writes:

Good practical training should only be given where there is good clinical care. Absence of care to that standard will mean that training is deficient. Therefore, there is an inextricable link between the two

Since the publication of the Francis report there has been a significant focus on driving up the quality of care during a time of significant economic austerity. ${ }^{6}$ What can we say about the relationship between clinical education and quality of patient care?

\section{QUALITY OF CARE AND TRAINING PRACTICES}

In a previous issue of the $B J G P$, we published data $^{7}$ that demonstrated that patients registered with a GP training practice reported greater satisfaction in consultations compared with those not registered with a training practice. Data were drawn from the General Practice Patient Survey (GPPS). We

\section{GP training has a fundamental role to play in improving patient outcomes [and] training the future GP.}

found that GP training practice status was a significant predictor of positive responses to all six GPPS questions in the doctor care domain' (Q21a-e, Q22) and to both of the questions relating to 'overall satisfaction' (Q28, Q29). Patients registered with GP training practices rated the doctor care domain' questions between 0.7-1.1\% higher than patients registered with non-training practices; they rated the "overall satisfaction questions $1.5-2.0 \%$ higher?

In further studies comparing training and non-training practices, Weston et al demonstrated that patients registered at training practices reported higher satisfaction in three domains: access, communication, and overall patient experience. ${ }^{8}$ However, lower levels of satisfaction with continuity of care were reported in training practices. Training practices achieved a mean of 11 Quality and Outcomes Framework (QOF) points more than non-training practices. Secondary care utilisation by training practices showed no significant difference in rates of emergency admissions, ambulatory care, sensitive admissions, or outpatient attendances. $A \& E$ attendance rates, however, were significantly lower in training than in nontraining practices, albeit with small absolute differences. Training practices were characterised by significantly higher cancer detection rates and cancer referral rates, putting training practices ahead in terms of early cancer diagnosis. Findings included somewhat lower cancer conversion rates la lower proportion of urgent cancer referrals eventually diagnosed as cancer), but this is an expected consequence of a higher referral rate in these practices. ${ }^{8}$

We have also demonstrated that GP training practices prescribe fewer antibiotics overall and fewer broad-spectrum antibiotics. ${ }^{9}$ Where training practice status influenced measures of patient care, the size of this effect was modest relative to factors such as deprivation, disease burden, demographics, and ethnicity.

These studies highlighting the association between GP training and patient outcomes are consistent with the definition of quality as stated by Lord Darzi in the 2008 review of the $\mathrm{NHS}^{10}$ covering patient experience (based on findings from the GP patient survey), patient safety (based on higher cancer detection rates), and clinical effectiveness (based on higher QOF scores, which could be taken as a surrogate marker of effectiveness; their lower antimicrobial prescribing may also indicate greater adherence to NICE prescribing guidance). Thus, the available evidence supports the assertion that an educational ethos has a positive effect on patient care.

\section{FUTURE DIRECTIONS}

There remain a significant number of unanswered questions in seeking to understand the relationship between training and patient care. For starters, are better-organised practices naturally inclined towards structured training. or is it that engagement with training (through accreditation and professional development) results in better patient care? As far back as the mid-1990s, Baker and Thompson determined that training practices (compared with non-training practices) had more sophisticated systems for care delivery, were more innovative, had higher levels of practice development, and that, over time, the gap between training and non-training practices had widened, not narrowed.11 This work, however, was not able to establish the influence of these differences upon patient care.

In times of economic austerity, questions are asked about the cost and effectiveness of training. Comparisons with other types of training and professional groups take place in the absence of robust evidence and without a focus on the cost-effectiveness of such public monies in education and training. There remains a place for robust and sophisticated economic evaluations of GP training and its impact on patient care. GP training can be seen as a standard bearer for high-quality primary care. However, austerity and service pressure contribute to real difficulties in maintaining quality within financial constraints, and subsequently impact on training. 
"GP training can be seen as a standard bearer for high-quality primary care. However, austerity and service pressure contribute to real difficulties in maintaining quality within financial constraints, and subsequently impact on training.

There are many more questions: Does GP training offer opportunities for developing and retaining our workforce beyond the act of training the next generation and improving patient outcomes? Could increased flexibility in the provision of GP training encourage GPs (and others) who might otherwise consider retiring or leaving the profession to remain engaged, thus sharing their wisdom with younger colleagues as well as benefiting patients? We need more research into the organisational aspects of training practices and the influence of training on the GP workforce.

\section{CONCLUSION}

We believe that GP training has a fundamental role to play in improving patient outcomes as well as training the future GP. It has the potential to extend its influence further into retaining more of our workforce, as well as sharing our collective educational expertise with the broader range of learners who would benefit immensely. For us, the future of GP training is bright.

\section{Sanjiv Ahluwalia,}

Postgraduate Dean, Health Education England, London.

\section{Elizabeth Hughes,}

Deputy Medical Director, Health Education England, London.

\section{Mark Ashworth,}

Reader in Primary Care, School of Population Health and Environmental Sciences, King's College London, London.

\section{Provenance}

Freely submitted; externally peer reviewed.

\section{Competing interests}

Sanjiv Ahluwalia and Elizabeth Hughes work for Health Education England, which manages GP training. Mark Ashworth has declared no competing interests.

DOI: https://doi.org/10.3399/bjgp19X701921

\section{ADDRESS FOR CORRESPONDENCE}

Sanjiv Ahluwalia

Health Education England, Stewart House, 32 Russell Square, London WC1B 5DN, UK.

\section{Email: sanjiv.ahluwalialanhs.net}

\section{REFERENCES}

1. Starfield B, Shi L, Macinko J. Contribution of primary care to health systems and health. Millbank Q2005; 83(3): 457-502.

2. NHS England. General Practice Forward View. 2016. https://umw.england.nhs.uk/gp/gpfv/ laccessed 26 Feb 2019).

3. Health Education England. Record breaking number of doctors entering GP specialty training. 2017. https://hee.nhs.uk/news-blogsevents/news/record-breaking-number-doctorsentering-gp-specialty-training laccessed $26 \mathrm{Feb}$ 2019).

4. General Medical Council. Training environments 2017: key findings from the national training surveys. GMC, 2017. https:// unw.gmc-uk.org/-/media/documents/ntsreport-20173_pdf-72689147.pdf laccessed 26 Feb 2019).

5. Francis R. The Mid Staffordshire NHS Foundation Trust Public Inquiry. London: The Stationery Office, 2013. http://webarchive. nationalarchives.gov.uk/20150407084003/http:// unw.midstaffspublicinquiry.com laccessed 26 Feb 2019).

6. Department of Health and Social Care. $A$ promise to learn - a commitment to act: improving the safety of patients in England. 2013.

7. Ashworth M, Schofield P. Durbaba S, Ahluwalia S. Patient experience and the role of postgraduate GP training: a cross-sectional analysis of national Patient Survey data in England. Br J Gen Pract 2014; DOI: https://doi. org/10.3399/bjgp14X677545.

8. Weston C, Ahluwalia S, Bassett P, et al. GP training practices in England: a description of their unique features based on national data. Educ Prim Care 2017; 28(6): 313-318.

9. Ahluwalia S, Sadak M, Ashworth M. Antimicrobial prescribing in post-graduate training practices: a cross-sectional study of prescribing data in general practices in England. Educ Prim Care 2018; 29(3): 139-143.

10. Department of Health. High quality care for all. NHS Next Stage Review final report. 2008. https://assets.publishing.service.gov. uk/government/uploads/system/uploads/ attachment_data/file/228836/7432.pdf [accessed 26 Feb 2019].

11. Baker R, Thompson J. Innovation in general practice: is the gap between training and nontraining practices getting wider? Br J Gen Pract 1995; 45(395): 297-300. 